\title{
Tilt records prior to the 2011 off the Pacific coast of Tohoku Earthquake
}

\author{
Hitoshi Hirose \\ National Research Institute for Earth Science and Disaster Prevention, 3-1 Tenno-dai, Tsukuba, Ibaraki, Japan
}

(Received April 9, 2011; Revised May 9, 2011; Accepted May 10, 2011; Online published September 27, 2011)

\begin{abstract}
The 2011 off the Pacific coast of Tohoku Earthquake was an unexpected megathrust event with magnitude 9.0 along the Japan trench. Hi-net tilt records prior to the great earthquake are examined in order to determine whether a precursory tilt change is observed in the short-term ( $\sim$ days) and medium-term $(\sim$ a month) for confirming a preslip hypothesis and the effectiveness of an earthquake prediction method based on that hypothesis. For a quantitative reference to the observation, the detectability of the tilt observation for interplate slip on the subducting Pacific plate is also evaluated. In this study, no clear signal of preseismic tilt change or preslip is found in the records. This means that there is no preslip larger than moment magnitude $\left(M_{\mathrm{w}}\right) 6.2$ on the deeper extension of the earthquake source area on the plate interface or larger than $M_{\mathrm{w}} 7.3$ near the hypocenter.
\end{abstract}

Key words: Preseismic crustal deformation, preslip, earthquake prediction, NIED Hi-net.

\section{Introduction}

The 2011 off the Pacific coast of Tohoku Earthquake (M 9.0) occurred at 14:46 on March 11 (Japan Standard Time, JST) along the Japan trench where the Pacific plate is subducting beneath overriding northeastern Japan. The earthquake and the accompanying gigantic tsunami have caused tremendous damage and over 10,000 casualties. This is the largest earthquake quantitatively estimated in and around Japan and is far beyond any prognoses provided by the Earthquake Research Committee under the Headquarters for Earthquake Research Promotion of the Japanese government, which has evaluated the long-term probabilities of earthquake occurrence for each of several segments in the source region of this great earthquake (ERC, 2002, 2009).

A "preslip" hypothesis is proposed in terms of earthquake prediction (e.g., Kamigaichi and Tsukada, 2006). The preslip is thought to be a quasi-static preseismic slip that would lead to the main earthquake rupture (e.g., Yoshida and Kato, 2005). A controversial observational example of preslip is that large misclosures in the leveling survey just a few days before the 1944 Tonankai earthquake are interpreted as the accelerating tilt deformation caused by the preslip of the earthquake (Mogi, 1984; Linde and Sacks, 2002). However, there is a possibility that the observed misclosures are observational errors (Sagiya, 2004). Measurements with borehole strainmeters and other high-precision instruments for inland earthquakes have also shown no indication of clear precursory deformation (Johnston et al., 1987, 2006). Thus it should be noticed that there is no clear and widely accepted observational evidence of preslip.

This paper investigates tilt records prior to the 2011 To-

Copyright (C) The Society of Geomagnetism and Earth, Planetary and Space Sciences (SGEPSS); The Seismological Society of Japan; The Volcanological Society of Japan; The Geodetic Society of Japan; The Japanese Society for Planetary Sciences; TERRAPUB.

doi:10.5047/eps.2011.05.009 hoku Earthquake observed with high sensitivity accelerometers (tiltmeters) at National Research Institute for Earth Science and Disaster Prevention (NIED) Hi-net stations in order to examine possible preseismic deformation. The detectability of the Hi-net tilt observation for slip on the plate interface is also evaluated for a quantitative measure of the observation. This is important not only to test the effectiveness of a short-term earthquake prediction strategy based on the monitoring of preslip with crustal deformation observations, but also to constrain a physical process immediately before a dynamic rupture initiation of an earthquake.

\section{Tilt Data before the Mainshock}

NIED Hi-net tiltmeter records (Okada et al., 2004; Obara et al., 2005) are used to investigate possible crustal deformations before the earthquake (in this paper, times are presented in Japan Standard Time, JST). Figure 1 shows the station locations of the NIED Hi-net stations equipped with a tiltmeter. Since the duration of a possible preslip is unknown, two time intervals are assumed: (1) shortterm ( $\sim$ days $)$, and $(2)$ medium-term $(\sim$ a month $) . \quad$ The original data, which were recorded at a sampling rate of $20 \mathrm{~Hz}$, are resampled to those for one minute for data (1) and one hour for data (2) by averaging. A sensor direction is then corrected for each station based on teleseismic waves (Shiomi et al., 2003). Tidal components are estimated and removed with the BAYTAP-G program (Tamura et al., 1991). An atmospheric pressure response is also removed with BAYTAP-G for the medium-term records (2) based on hourly-observed atmospheric pressure data at a meteorological observatory of the Japan Meteorological Agency (Morioka for group A, and Fukushima for group B in Fig. 1).

On March 9, two days before the mainshock, a magnitude 7.3 earthquake occurred at 11:45 (JST) about $50 \mathrm{~km}$ northeast of the epicenter of the mainshock. The focal mechanism solution of the March 9 event shows a shallow thrust 


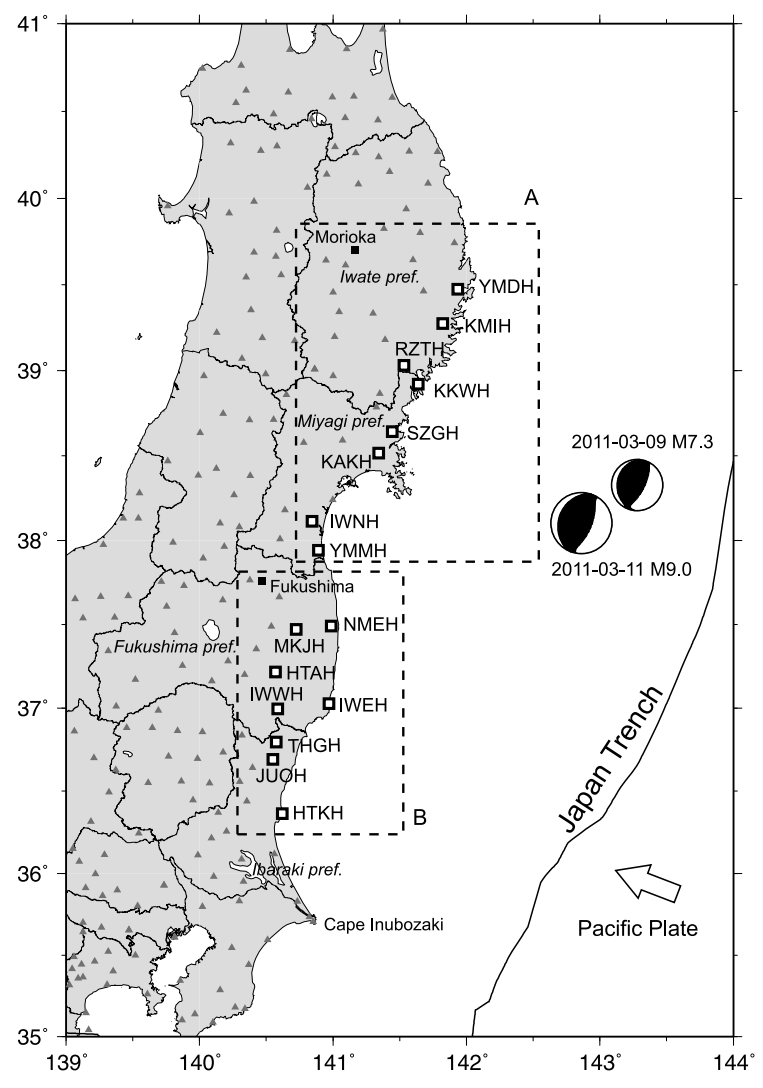

Fig. 1. Index map showing the station locations. Open squares and grey triangles show the locations of NIED Hi-net tiltmeter stations. Solid squares denote the locations of the JMA meteorological observatories. The NIED F-net focal mechanisms (NIED, 2011) of the March 9 large earthquake and the March 11 great earthquake are shown.

type fault motion (Fig. 1), indicating that this earthquake is an interplate event. This large earthquake caused a jump in tilt records at many stations. A pendulum-type tiltmeter, which is equipped at Hi-net stations, sometimes shows a jump that cannot simply be explained by a static deformation in an elastic medium caused by an earthquake fault dislocation in its output when the sensor is hit by a large seismic wave. The coseismic jump caused by the March 9 earthquake is then corrected in each trace.

Figure 2 shows the detided tilt records for selected stations for the short term data (1) from March 8 to 11 . The most prominent feature before the mainshock are the large seismic waves from the March 9 earthquake and the subsequent aftershocks. If preslip occurred, an accelerating (nonlinear, exponentially increasing) tilt change would have been expected before the earthquakes (e.g., Kato, 2003). However, any clear precursory changes that exceeds a fluctuation level are not seen before the March 9 earthquake nor the mainshock. The longer-term tilt records, the mediumterm data (2), from February 1 are shown in Fig. 3. Although some small fluctuations of remaining atmospheric pressure response, rainfalls, and/or unidentified origins are seen in the records at several stations, no clear preseismic deformation is observed. This is also the case for the records at other stations that are not displayed in the figures. It is therefore concluded that possible preslip just before the mainshock did not cause significant tilt changes, if any.

\section{Detectability for Slip on the Plate Interface}

It is important to examine how large the preslip could be that is not detectable with the present observation network in order not only to improve a strategy for earthquake prediction, but also to constrain the physical process of earthquake initiation. The detectability of interplate slip on the subducting Pacific plate over the source area of the mainshock is evaluated based on the Hi-net tiltmeter network. The condition of slip detection is defined as a significant tilt deformation larger than $0.1 \mu \mathrm{rad}$ computed at three or more stations. The theoretical tilt deformation is calculated with Okada's (1992) analytical expression for a double-couple point source in an elastic half-space. The plate configuration of the subducting Pacific plate compiled by ERC (2002) is assumed. The focal mechanism of the interplate slip is assumed to have a reverse fault with the slip direction opposite to the relative plate motion of the Pacific plate with respect to the Okhotsk plate (Sella et al., 2002; Fig. 1).

Figure 4 shows the lower bounds of moment magnitude $\left(M_{\mathrm{w}}\right)$ of detectable slip with the Hi-net tiltmeter network. Although the smallest $M_{\mathrm{w}}$ of 6.1 is evaluated near Cape Inubozaki because of the relatively shallower plate boundary beneath the stations onshore and the closest stations among the evaluated area, this indicates that a slip of $M_{\mathrm{w}} 6.2-6.5$ or larger is required for detection along the east coast. This also shows that the condition of detection is worse in the shallower zone around the hypocenters of the mainshock and the March 9 earthquake. In other words, if the preslip occurred before the mainshock, the size of the preslip must be smaller than $M_{\mathrm{w}} 7.3$ near the hypocenter of the mainshock and smaller than $M_{\mathrm{w}} 6.2$ on the deeper extension of the source area on the plate interface.

Note that the detectability of interplate slip with the GEONET GPS network operated by the Geospatial Information Authority of Japan (GSI) is estimated as $M_{\mathrm{w}} \sim 6.5$ around the Miyagi prefecture area, which can cause $3 \mathrm{~mm}$ or larger displacements at three or more GEONET stations (GSI, 2010).

\section{Discussion}

The Hi-net tiltmeters have successfully detected the tilt deformations caused by slow slip events (SSE) in the southwest Japan subduction zone (e.g., Obara et al., 2004; Hirose and Obara, 2005). The typical tilt change of $\sim 0.1 \mu \mathrm{rad}$ is observed when a $M_{\mathrm{w}} \sim 6.0$ SSE occurs at around $30 \mathrm{~km}$ depth. This indicates that the detectability for interplate slip on the subducting Pacific plate is worse than the cases for the SSEs in southwest Japan based on the onshore tilt measurement, and therefore if a similar slip episode with the same size as the SSEs occurs on the Pacific plate interface, it could not be detected. This is mainly due to the difference in the depths of the plate interfaces. In order to improve the detectability, observation of crustal deformation on an ocean floor is a useful tool to monitor the slip on the plate interface because the depth of the interface is shallower in an offshore region than onshore.

The detectability shown in Fig. 4 indicates that the tilt observation network could be useful for monitoring ongoing afterslip following the great earthquake (GSI, 2011), which might trigger a nearby large earthquake such as the slip af- 

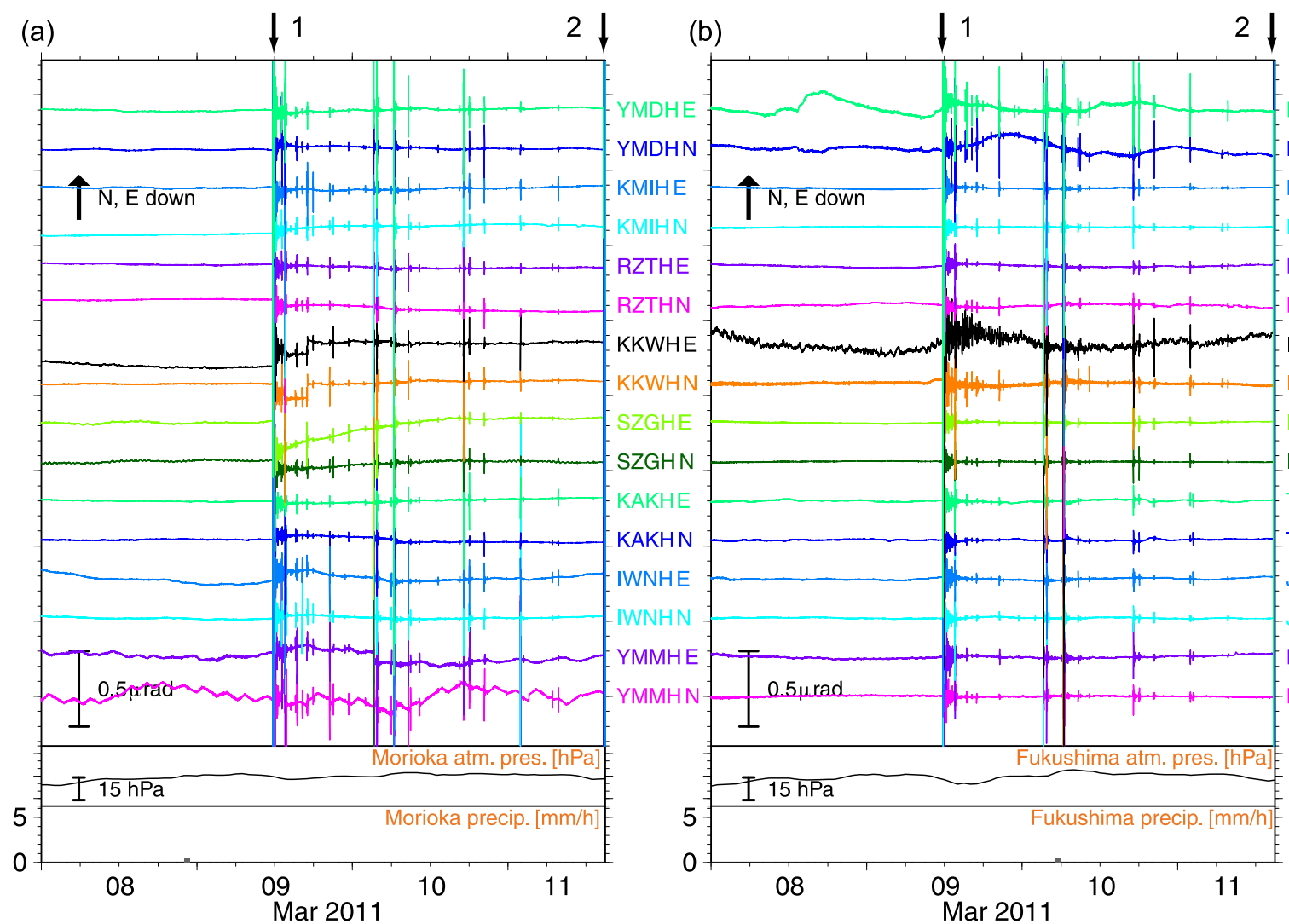

Fig. 2. Detided tilt records from March 8, 2011 prior to the mainshock. (a) Records at stations in group A. (b) Records at stations in group B. The station groups are shown in Fig. 1. The sampling rate of these records is one minute. Atmospheric pressure changes and hourly precipitation at Morioka and Fukushima meteorological observatories of JMA are also plotted. The origin times of (1) the March 9 earthquake, and (2) the mainshock are indicated as solid arrows on the top of each frame.

(a)

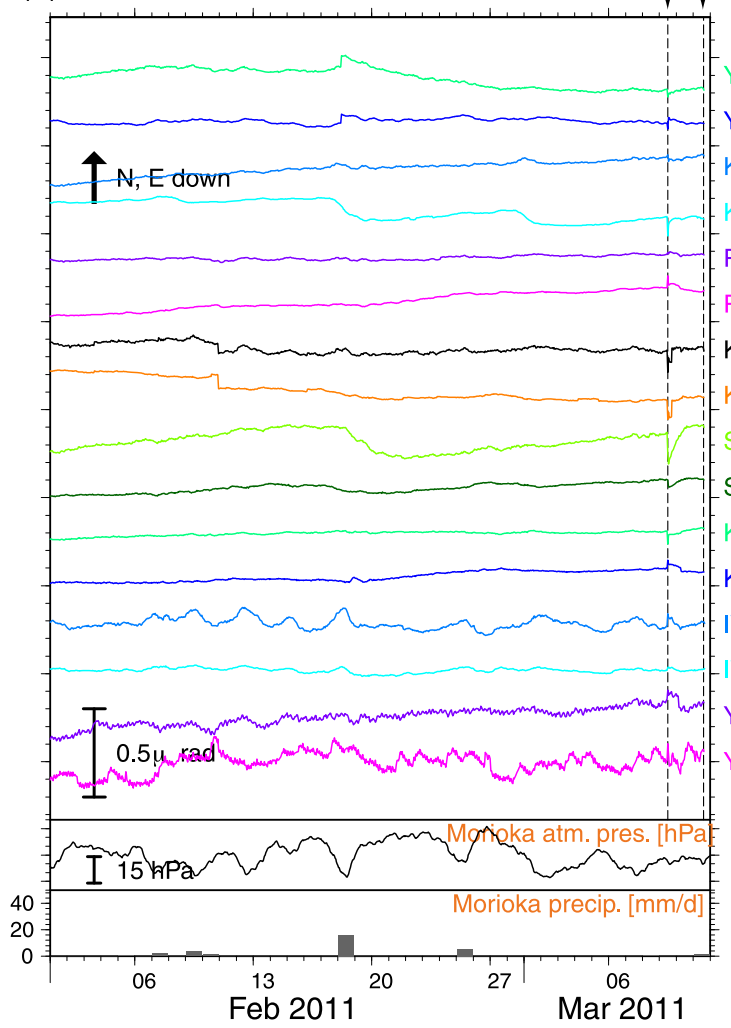

(b)

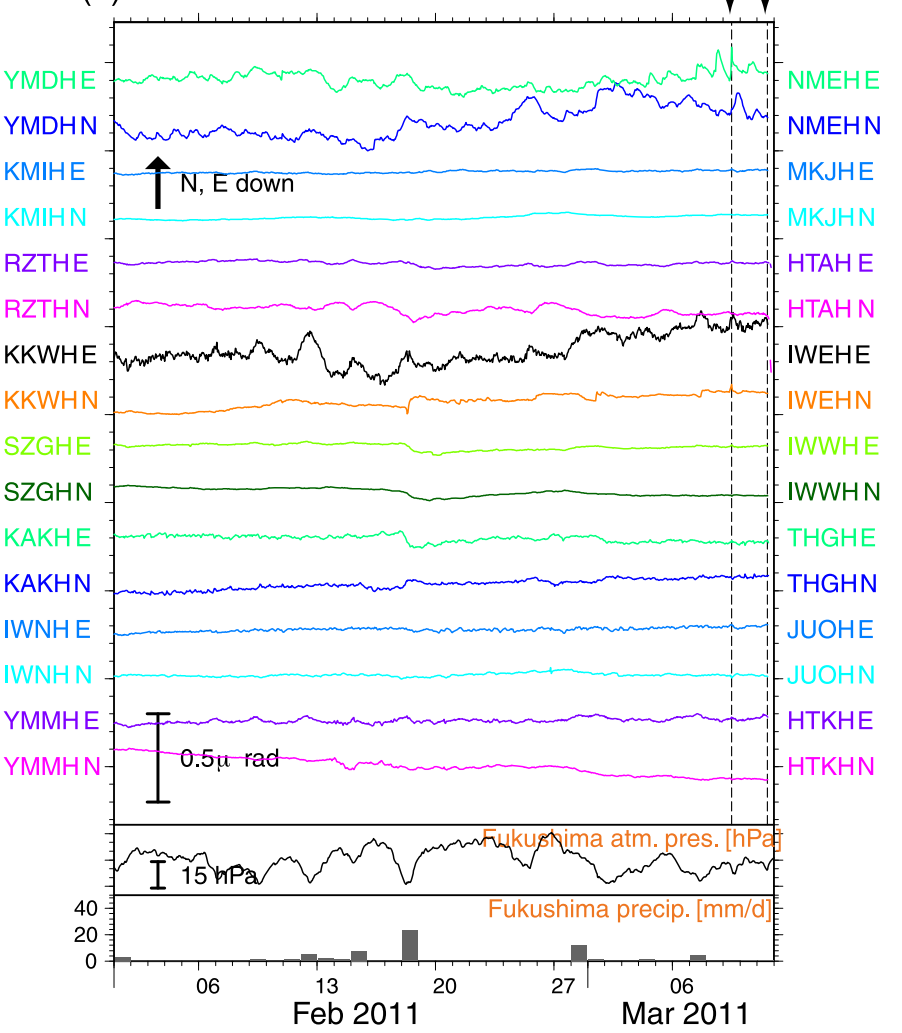

Fig. 3. Same as Fig. 2, but for detided and atmospheric pressure response-corrected tilt records from February 1, 2011 prior to the mainshock. The sampling rate of these records is one hour. 


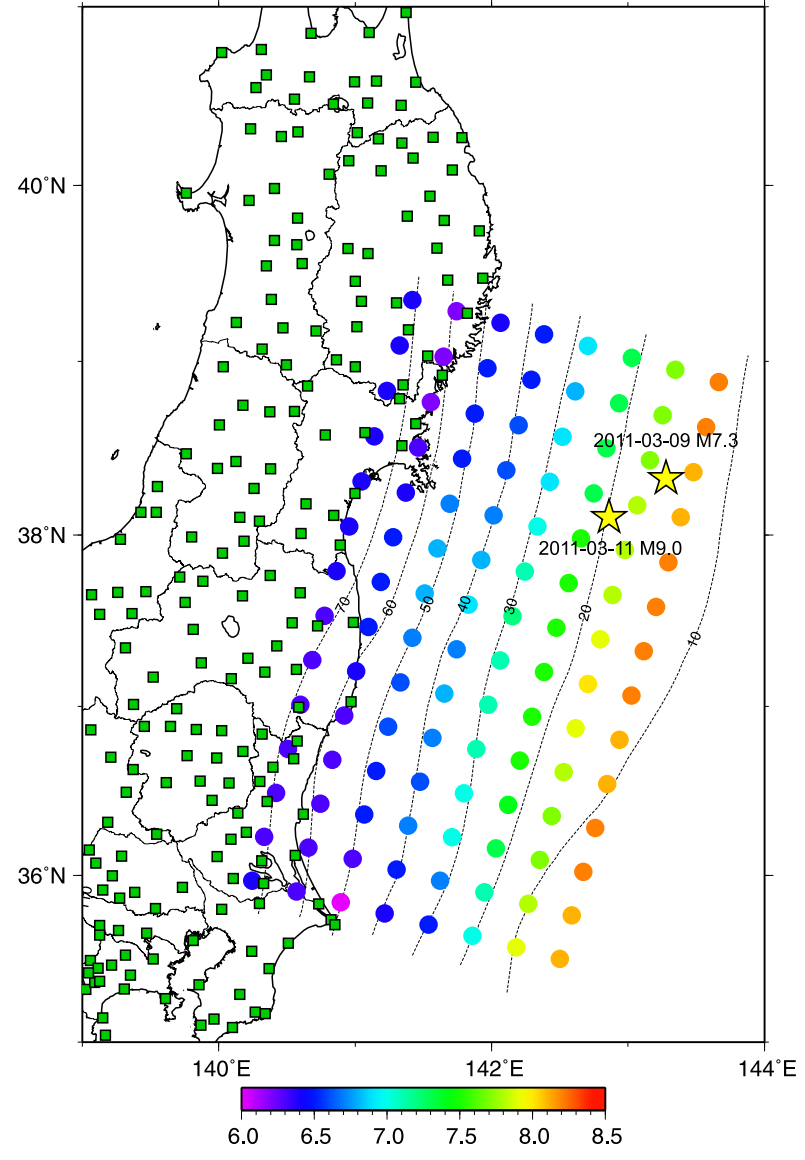

Fig. 4. Detectability of interplate slip on the interface on the subducting Pacific plate. Color scale indicates the lower bounds of corresponding moment magnitude of detectable slip with the Hi-net tiltmeter stations indicated as green squares.

ter the 2003 Tokachi-oki earthquake ( $M$ 8.0) which could have triggered the 2004 Kushiro-oki earthquake (M 7.1) (Murakami et al., 2006). It is important to monitor the afterslip in order to evaluate the stress change on possible earthquake sources.

The fact that there is no clear evidence of preseismic crustal deformation for the magnitude 9.0 great earthquake is a very serious problem for the realization of a shortterm earthquake prediction method, and therefore this may require a change of the prediction strategy. Nevertheless, further examinations of recorded data are important to learn as much as possible from this rare event and to improve monitoring ability in the future.

Acknowledgments. I am grateful to all of the members of the Earthquake and Volcano Data Center at NIED for maintaining Hinet to make the valuable dataset available. I would like to thank D. Agnew, H. Suito and editor-in-chief K. Yomogida for useful manuscript reviews. Meteorological data were provided by Japan Meteorological Agency. The Generic Mapping Tools (Wessel and Smith, 1998) were used for creating the figures.

\section{References}

Earthquake Research Committee (ERC), Long-term probabilities for seis- micity along the Japan trench from off Sanriku to off the Boso peninsula, 2002 (in Japanese).

Earthquake Research Committee (ERC), Long-term probabilities for seismicity along the Japan trench from off Sanriku to off the Boso peninsula (revised), 2009 (in Japanese).

Geospatial Information Authority of Japan (GSI), Detectability of slip on a plate boundary based on GEONET, Rep. Coord. Commit. Eq. Pred., 84, 565-576, 2010 (in Japanese).

Geospatial Information Authority of Japan (GSI), The 2011 off the Pacific coast of Tohoku Earthquake: postseismic slip distribution model (preliminary), http://www.gsi.go.jp/cais/topic110315.2-index-e.html, 2011.

Hirose, H. and K. Obara, Repeating short- and long-term slow slip events with deep tremor activity around the Bungo channel region, southwest Japan, Earth Planets Space, 57, 961-972, 2005.

Johnston, M. J. S., A. T. Linde, M. T. Gladwin, and R. D. Borcherdt, Fault failure with moderate earthquakes, Tectonophysics, 144, 189-206, 1987.

Johnston, M. J. S., R. D. Borcherdt, A. T. Linde, and M. T. Gladwin, Continuous borehole strain and pore pressure in the near-field of the September 28, 2004 Parkfield Earthquake: Implications for nucleation, fault response, earthquake prediction and tremor, Bull. Seismol. Soc. Am., 96, S56-S72, 2006.

Kamigaichi, O. and S. Tsukada, JMA's strategy for short-term prediction of the great Tokai earthquake and the new information framework, Zisin, 2nd ser., J. Seismol. Soc. Jpn., 59, 61-67, 2006 (in Japanese with English abstract).

Kato, N., A possible model for large preseismic slip on a deeper extension of a seismic rupture plane, Earth Planet. Sci. Lett., 216, 17-25, 2003.

Linde, A. T. and I. S. Sacks, Slow earthquakes and great earthquakes along the Nankai trough, Earth Planet. Sci. Lett., 203, 265-275, 2002.

Mogi, K., Temporal variation of crustal deformation during the days preceding a thrust-type great earthquake-The 1944 Tonankai Earthquake of magnitude 8.1, Japan, Pure Appl. Geophys., 122, 765-780, 1984.

Murakami, M., H. Suito, S. Ozawa, and M. Kaidzu, Earthquake triggering by migrating slow slip initiated by M8 earthquake along Kuril Trench, Japan, Geophys. Res. Lett., 33, doi:200610.1029/2006GL025967, 2006.

National Research Institute for Earth Science and Disaster Prevention (NIED), F-net moment tensor catalog, http://www.fnet.bosai.go.jp/, 2011.

Obara, K., H. Hirose, F. Yamamizu, and K. Kasahara, Episodic slow slip events accompanied with non-volcanic tremors in southwest Japan subduction zone, Geophys. Res. Lett., 31(23), L23602, doi:10.1029/2004GL020848, 2004.

Obara, K., K. Kasahara, S. Hori, and Y. Okada, A densely distributed highsensitivity seismograph network in Japan: Hi-net by National Research Institute for Earth Science and Disaster Prevention, Rev. Sci. Instrum., 76, 021301, doi:10.1063/1.1854197, 2005.

Okada, Y., Internal deformation due to shear and tensile faults in a halfspace, Bull. Seismol. Soc. Am., 82, 1018-1040, 1992.

Okada, Y., K. Kasahara, S. Hori, K. Obara, S. Sekiguchi, H. Fujiwara, and A. Yamamoto, Recent progress of seismic observation networks in Japan-Hi-net, F-net, K-NET, and KiK-net—, Earth Planets Space, 56, xv-xxviii, 2004.

Sagiya, T., Precursory crustal deformation of the 1944 Tonankai Earthquake revisited, Monthly Chikyu, 26(11), 746-753, 2004 (in Japanese).

Sella, G. F., T. H. Dixon, and A. Mao, REVEL: A model for recent plate velocities from space geodesy, J. Geophys. Res., 107(B4), doi:10.1029/2000JB000033, 2002.

Shiomi, K., K. Obara, S. Aoi, and K. Kasahara, Estimation on the azimuth of the Hi-net and KiK-net borehole seismometers, Zisin, 2nd ser., J. Seismol. Soc. Jpn., 56, 99-110, 2003 (in Japanese).

Tamura, Y., T. Sato, M. Ooe, and M. Ishiguro, A procedure for tidal analysis with a Bayesian information criterion, Geophys. J. Int., 104, 507-516, 1991.

Wessel, P. and W. H. F. Smith, New, improved version of the Generic Mapping Tools released, Eos Trans. AGU, 79, 579, 1998.

Yoshida, S. and N. Kato, Dependence of preslip on eventual earthquake size, Zisin, 2nd ser., J. Seismol. Soc. Jpn., 58, 231-246, 2005 (in Japanese with English abstract).

H. Hirose (e-mail: hirose@bosai.go.jp) 